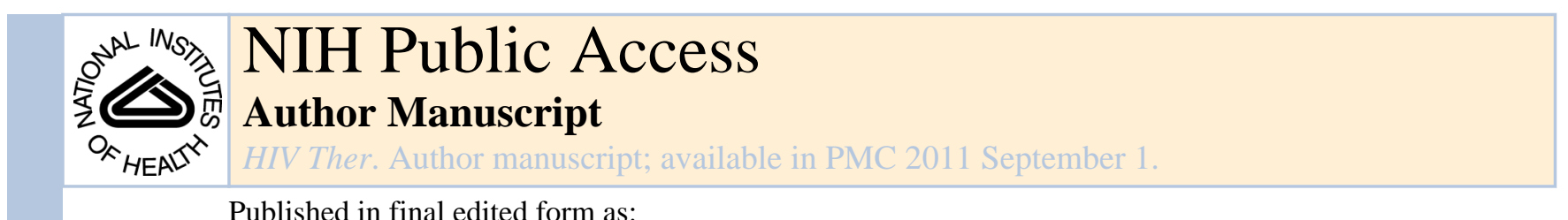

Published in final edited form as:

HIV Ther. 2010 November ; 4(6): 639-647. doi:10.2217/hiv.10.51.

\title{
Regulatory T cells in HIV immunotherapy
}

\author{
Bernard JC Macatangay ${ }^{1}$ and Charles R Rinaldo ${ }^{\dagger}$ \\ ${ }^{1}$ HIV/AIDS Program, Division of Infectious Diseases, University of Pittsburgh School of Medicine, \\ Pittsburgh, PA, USA
}

\begin{abstract}
Significant research has been conducted on the role of regulatory T cells (Tregs) in HIV infection. To date, however, it is not clear whether Tregs play a detrimental role or a beneficial role in the pathogenesis of HIV infection. In fact, a number of immunotherapeutic strategies to control HIV infection have revealed a possible antagonistic role for Tregs. This necessitates investigating ways to counteract the suppressive function, such as through Treg depletion or blockade of specific Treg immunosuppressive mechanisms, without further increasing the cellular immune activation associated with chronic HIV infection. Simply applying Treg immunotherapeutic strategies used in diseases other than HIV may pose problems due to the complexity of HIV immunopathogenesis. Studies are therefore necessary to elucidate the different immunoregulatory networks in HIV infection in order to determine the specific cellular or molecular pathways that can be altered to boost the body's immune control of HIV.
\end{abstract}

\section{Keywords}

HIV; immunotherapy; Treg

\begin{abstract}
In the mid-1990s, the re-emergence of a T-cell subpopulation capable of immune suppression and maintenance of peripheral immune tolerance [1-3] ushered in significant research on the role of these regulatory $\mathrm{T}$ cells (Tregs) in a variety of medical conditions. Tregs are classified as either naturally occurring (nTreg), which arise from the thymus throughout life as a functionally mature population, or inducible Tregs (iTregs), which develop peripherally from naive $\mathrm{T}$ cells in the presence of specific antigens, certain cytokines and antigen-presenting cells [4-6]. The basic Treg phenotype has been characterized by the expression of the IL-2 receptor $\alpha$-chain CD25 $[1,7]$ and the transcription factor forkhead box P3 (FOXP3) [8]. Other Treg markers have been implicated in Treg suppressive function, including expression of the cytotoxic $\mathrm{T}$ lymphocyte-associated antigen (CTLA)-4 [9], the glucocorticoid-induced tumor necrosis factor receptor familyrelated (GITR) gene [10] and the ectonucleotidase CD39 [11-13].
\end{abstract}

Unlike the early suppressor T cells, which lost favor in the 1980s owing to lack of reliable markers and a molecular basis of suppression [3], a number of studies have shown various

\footnotetext{
(C) 2010 Future Medicine Ltd

${ }^{\dagger}$ Author for correspondence: Department of Infectious Diseases \& Microbiology, University of Pittsburgh Graduate School of Public Health, University of Pittsburgh School of Medicine, Pittsburgh, PA, USA, rinaldo@ pitt.edu.

Financial \& competing interests disclosure The authors have no other relevant affiliations or financial involvement with any organization or entity with a financial interest in or financial conflict with the subject matter or materials discussed in the manuscript. This includes employment, consultancies, honoraria, stock ownership or options, expert testimony, grants or patents received or pending, or royalties.

No writing assistance was utilized in the production of this manuscript.
} 
mechanisms by which Tregs exert immune suppression. Their increased expression of CD25 allows them to compete with other T cells for IL-2 [14], thereby inhibiting T-cell proliferation. Apart from this, they suppress effector T-cell responses through direct cell contact by CTLA-4 binding to dendritic cells (DCs). This binding leads to DC production of indoleamine 2,3-deoxygenase (IDO) [15], resulting in the consequent deprivation of the essential amino acid tryptophan and the accumulation of tryptophan catabolic products. Tregs have also been shown to secrete the inhibitory cytokines IL-10 and TGF- $\beta$ [16], facilitate adenosine production $[11,13]$ and utilize cytolytic molecules granzyme B and perforin [17], all of which mediate immune regulation. Knowledge about Treg's suppressive function has given investigators insight into better strategies for immunotherapy of autoimmune diseases, cancer and chronic infections such as HIV.

\section{Tregs in HIV infection}

A number of studies have investigated Tregs in HIV infection by assessing their frequency and number in peripheral blood, mucosa and lymphoid tissue $[18,19]$. Results have varied in part because no single set of Treg markers has been consistently used. Nevertheless, there is usually an increased frequency of Tregs in lymphoid tissues of HIV-infected persons $[20,21]$. This lymphoid tissue accumulation may be caused by the binding of Treg to HIV gp120, leading to an upregulation of Treg homing factors for lymph nodes and mucosa [22]. In fact, soluble gp120 has been shown to functionally activate Tregs [23].

To date, it is still not clear whether Tregs are detrimental to HIV infection because they suppress HIV-specific responses, or if they are beneficial because they decrease immune activation associated with HIV infection. HIV binding to Tregs not only allows the cells to migrate and accumulate in lymphoid tissues and mucosa, it also increases Treg suppressive function [22]. Tregs isolated from HIV-infected individuals suppress the anti-HIV CD8 ${ }^{+} \mathrm{T}$ cell cytolytic and $\mathrm{CD} 4^{+} \mathrm{CD} 25^{-}$proliferation responses [20,24]. Moreover, Thorborn et al. have shown that $\mathrm{CD}^{+} \mathrm{T}$ effector cells have increased sensitivity to Treg suppression, thus compensating for decreased peripheral blood Treg numbers in HIV-1 infection [25]. On the other hand, numbers of Treg are inversely correlated with CD38 expression on CD8 ${ }^{+} \mathrm{T}$ cells $[26,27]$, which, in turn, has been associated with shorter survival in advanced HIV disease [28]. In fact, in a study using the simian immunodeficiency virus (SIV)-macaque model, blocking CTLA-4 led to increased immune activation and viral replication, mostly at the mucosal sites [29]. The contrasting effects as a result of Treg depletion in HIV infection are clearly illustrated in the study by Weiss et al. (National Agency for AIDS Research [ANRS] 116), where after 12 months of treatment interruption, the decrease in the absolute numbers of Tregs resulted in a failure. However, the depletion of $\mathrm{CD} 4{ }^{+} \mathrm{CD} 25^{+}$cells also led to an increase in the lymphoproliferative responses of most of the study participants [30].

Recent studies have investigated interactions between Tregs and T-helper (Th)17 cells, which secrete IL-17 and are important for protection against fungal and extracellular bacterial infections. Results with the SIV model show an increased frequency of Tregs in lymphoid tissues together with the preferential depletion of Th17 cells [31]. This leads to a loss of balance between these two T cell subsets in pigtailed macaques with pathogenic SIV infection [32]. A profound depletion of peripheral blood Th17 cells, contrasted with a gradual decline in Tregs, is also found in HIV-1 infected individuals [33]. Interestingly, Favre et al. have reported that IDO production by DCs, specifically the tryptophan catabolite kynurenine, is associated with this loss of balance, and leads to increased Treg numbers [34]. Kynurenine levels were positively correlated with both viral load and immune activation. Since Tregs also mediate suppression through production of IDO by DCs following CTLA-4 binding, tryptophan catabolism could then lead to a cycle of Treg expansion and immunosupression. Moreover, in a nested case-control study within the 
Multicenter AIDS Cohort Study (MACS), expansion of Treg in untreated HIV-1 patients was associated with an elevated percentage and median fluorescence intensity of CD38 expression in $\mathrm{CD}^{+} \mathrm{T}$ cells [35], again supporting the detrimental effect of Tregs in the course of the infection.

\section{HIV immunotherapy \\ Cytokine-based therapies}

IL-2-Although initial studies showed that intermittent infusions of IL-2 led to increased $\mathrm{CD}^{+} \mathrm{T}$ cell count $[36,37]$, recent trials using daily IL-2 administration in combination with either single or dual nucleoside therapy [38] or therapeutic vaccination [39] showed no benefit. Abrams et al. reported that despite significant increases in $\mathrm{CD} 4^{+} \mathrm{T}$ cell count in the IL-2 plus antiretroviral therapy (ART) arm, no clinical benefit was observed in two IL-2 clinical trials [40].

IFN- $\alpha-$ Clinical trials show that polyethylene glycol (PEG)-ylated IFN- $\alpha$ has anti-HIV activity. However, plasma viremia was not significantly different from baseline 6 weeks after stopping therapy, and no change was observed in $\mathrm{CD} 4^{+} \mathrm{T}$ cell numbers at the end of IFN- $\alpha$ treatment [41]. Moreover, post-treatment lymphocyte proliferation in response to different antigens was not different from baseline.

IL-7-IL-7 therapy results in increased numbers of circulating CD8 ${ }^{+}$and $\mathrm{CD} 4^{+} \mathrm{T}$ cell numbers following recombinant human IL-7 administration [42,43].

\section{Blockade of inhibitory receptors}

The discovery of inhibitory receptors, such as the programmed death receptor (PD)-1, and their role in T-cell dysfunction in the setting of chronic viral infections has led to in vitro studies blocking their regulatory ability [44-47]. The in vivo blocking of PD-1 in an SIVmacaque model showed an enhancement of virus-specific polyfunctional CD8 ${ }^{+} \mathrm{T}$-cell responses that correlated with a decrease in plasma viremia [48]. Although PD-1 blockade showed a novel way of boosting immune response to control the virus, the increase in the response was transient. By day 43 post-treatment, plasma viremia had returned to baseline levels. Breton et al., after observing an upregulation of the PD-1 ligands (PD-L1 and PD-L2) in monocyte-derived DCs following maturation, attempted a specific knockdown of the ligands by electroporation with a single siRNA sequence during the monocyte and immature stages of DC development [49]. When these DC were cocultured with peripheral blood mononuclear cells and pools of $15 \mathrm{mer}$ Gag peptides, the investigators noted a modest enhancing effect.

\section{Therapeutic vaccination}

Unlike cytokine-based strategies and blockade of inhibitory receptors, therapeutic vaccination is geared towards a more HIV-specific boosting of the immune response. Several clinical trials have utilized the potent antigen-presenting capability of DCs that allows them to activate pathogen-specific T-cell responses. Studies were aimed at enhancing anti-HIV responses in infected subjects by loading autologous DCs with HIV-specific peptides, RNA, or autologous, inactivated virus [50-52]. Connolly et al. used autologous DCs loaded with HIV peptides in ART-treated subjects and showed a transient increase in the frequency of IFN- $\gamma$-producing T cells following vaccination [50]. Lu et al. loaded DCs with autologous inactivated virus and showed decreased plasma HIV viremia (median of $80 \%$ ) during the first 112 days following administration of the vaccine [52]. The antiviral effect was shown to correlate with HIV-specific IL- 2 and IFN- $\gamma$-producing CD4 ${ }^{+} \mathrm{T}$ cells. In the clinical trial by Garcia et al., subjects on ART also received DCs loaded with autologous 
inactivated virus, and underwent an analytic treatment interruption following the vaccine [53]. A $0.5 \log _{10}$ decrease in plasma viremia compared with baseline was noted in only four of the 12 subjects. Finally, immunotherapy with HIV-RNA electroporated autologous DCs resulted in positive vaccine responses (i.e., $\mathrm{CD} 8^{+} \mathrm{T}$-cell proliferation in four out of nine subjects) [51]. Although there have been varying levels of success in these trials, a more consistent and long-lasting immune control of the virus after vaccine therapy is still needed.

\section{Tregs \& immunotherapy}

One mechanism by which Tregs suppress immune response is by competing with proliferating T cells for IL-2 for Treg growth and differentiation. Use of IL-2 immunotherapy could therefore expand Tregs, thereby blunting the expected immune benefits. Indeed, treatment of ovarian cancer patients with IL-2 showed proliferation of Tregs, with the expanding Treg population suppressing T-cell proliferation [54]. A similar observation was noted in HIV-infected patients receiving IL-2 therapy. In the IL-2-treated group, there was an expansion of $\mathrm{CD} 4^{+} \mathrm{T}$ cells expressing the Treg phenotype and with the molecular characteristics of Tregs [55]. These Tregs suppressed antigen-specific T-cell proliferation such that depletion of the Treg population led to significant increases in the proliferation of CD4CD25- T cells after stimulation with purified protein derivative and HIV p24 antigens. These results could explain why the large IL-2 studies conducted by Abrams et al. did not show benefits in clinical outcome despite increases in $\mathrm{CD} 4^{+} \mathrm{T}$ cell counts [40]. In the study by Ndhlovu et al., not only was there an increased Treg population in the HIVinfected subjects who received ART plus IL-2 compared with the group who received ART alone, the investigators also noted significantly decreased Gag-specific $\mathrm{CD} 8^{+}$and $\mathrm{CD} 4^{+} \mathrm{T}$ cells after IL-2 therapy [56]. By contrast, investigators studying recombinant human IL-7 therapy noted no increase in the frequency of Treg [43], but they also reported increased Tcell activation.

In the ACTG Study A5192, HIV-1 infected patients treated with PEGylated IFN- $\alpha$ exhibited significant decreases in plasma viremia and modest increases in $\mathrm{CD} 4^{+} \mathrm{T}$ cell counts while on therapy [41]. However, there was no significant change in lymphocyte proliferation with different antigens, including HIV-1 p24 and whole inactivated HIV-1 antigen. Interestingly, IFN- $\alpha$ and IL-10 induce the differentiation of type 1 regulatory cells from naive $\mathrm{CD} 4^{+} \mathrm{T}$ cells [57]. Type 1 regulatory cells are iTregs that suppress antigen-specific immune responses by IL-10 and TGF- $\beta$ production. In fact, a study on hepatitis $C$ virus (HCV) infection [58] observed increased production of IL-10 by peripheral blood mononuclear cells after antigen-specific stimulation in patients who received IFN- $\alpha$ monotherapy, suggesting an autoregulatory role of IL-10 in interferon therapy. These findings support the hypothesis that Tregs, specifically type 1 regulatory cells, are playing a role in the lack of lymphoproliferative response following IFN- $\alpha$ therapy.

The strategy of blocking PD-1 receptors presents a novel approach in HIV immunotherapy. Thus, blocking of PD-1 in the SIV model [48] and PD-L1 human DC in vitro [49] showed modest and transient enhancing effects. It is important to note, however, that PD-1 also negatively regulates $\mathrm{CD} 4{ }^{+} \mathrm{CD} 25^{+} \mathrm{FOXP} 3^{+}$Tregs in $\mathrm{HCV}$ infection $[59,60]$. In fact, in HIV infection, immune exhaustion, as shown by PD-1 upregulation, and immune activation have been associated with decreased Treg proliferation [61]. As such, immunotherapeutic strategies that would aim to block PD-1 to enhance HIV-specific CD8 ${ }^{+}$T-cell response may also inadvertently block PD-1 regulation of Treg function, thereby expanding these cells and allowing them to mediate their suppressive function. This increased suppression could counteract enhancement caused by the PD-1 blockade, thus causing only modest effects on the immune response. Tregs also promote tolerance in myeloid-derived DCs, thus causing 
suppression of effector T-cell function [62], further complicating the already complex regulatory network between DCs, Tregs and HIV-specific T cells in HIV infection.

In our initial HIV DC vaccine trial, vaccine responses assessed by ELISA were moderately increased after vaccination with HIV-peptide loaded DCs [50]. This response was transient. In a follow-up study, we analyzed the polyfunctional $\mathrm{CD}^{+} \mathrm{T}$-cell response to the vaccine (i.e., secretion of more than one immune mediator by the same cell), and observed no difference in the pre- and post-vaccine responses [63]. However, we noted a trend towards increased Treg frequency post-therapy. Importantly, upon depletion of Treg, there was a significant increase in $\mathrm{Gag}$-specific $\mathrm{CD} 8^{+} \mathrm{T}$-cell polyfunctional vaccine response. A similar antagonistic role of Tregs in DC-based vaccines has been shown for DC therapy of cancers $[64,65]$. Furthermore, in vitro studies indicate that in the presence of T-cell receptor stimulation, Tregs outcompete naive $\mathrm{CD} 4^{+} \mathrm{CD} 25^{-} \mathrm{T}$ cells in aggregating around $\mathrm{DCs}$, and subsequently inhibit DC maturation [66]. O'Gorman et al. have, in fact, reported that the initial phase of an immune response is an IL-2-dependent activation of FOXP3 ${ }^{+}$Tregs, and that antigen-specific T-cell activation took place only after repeated antigen exposure [67]. This may partially explain why repeated therapeutic DNA vaccination in an SIV-macaque model showed additional viral control benefit [68].

\section{Possible Treg immunotherapeutic strategies}

The antagonistic role that Tregs appear to play in the various immunotherapeutic strategies necessitates investigating ways of counter-acting their suppressive function. For example, administration of a cancer antigen peptide vaccine after $\mathrm{CD} 4^{+} \mathrm{CD} 25^{+} \mathrm{FOXP} 3^{+}$Treg depletion using the anti-CD25 monoclonal antibody (mAb) daclizumab induced cytotoxic lymphocytes [69]. However, in a DC vaccine study for metastatic melanoma, addition of daclizumab did not enhance the efficacy of the vaccine [70]. This is probably because activated T cells express CD25 and depleting them would mean depleting effector T cells that were induced by the vaccine. Inhibition of Treg may also be carried out by specifically inhibiting the mechanisms these cells use for suppression. In a mouse model of colon cancer, both depletion of CD25 $5^{+}$Tregs and CTLA-4 blockade increased carcinoembryonic antigen-specific immune responses following DC vaccination, with the vaccine becoming more effective when both strategies were used [71]. The use of an anti-GITR mAb is also being investigated in murine-tumor models. In this study, Coe et al. using in vivo labeling of GITR, showed increased Treg expression of GITR compared with conventional T cells, hence the preferential depletion of Tregs by DTA-1 [72].

Studies involving animal HIV models report significant findings regarding Treg blocking strategies. Morrow et al. compared IL-28B and IL-12 as adjuvants for DNA vaccination in a humanized mouse model of HIV infection [73]. Although both enhanced adaptive immunity, IL-28B also reduced the Treg population whereas IL-12 increased the Treg subset. It would be important to show whether simple reduction of Treg numbers can result in a more persistently enhanced anti-HIV response. In support of this, Thorborn et al. reported increased sensitivity of effector $\mathrm{T}$ cells to Tregs, thus compensating for the decreased peripheral Treg numbers in asymptomatic HIV-infected persons [25]. Administration of an anti-CTLA-4 antibody not only resulted in increased anti-SIV CD4 $4^{+}$and $\mathrm{CD} 8^{+}$effector function but also decreased viral RNA levels in lymph nodes [74]. This was likely due to decreased tissue levels of IDO and TGF- $\beta$. Inhibition of IDO alone in an HIV-1 encephalitis model using the IDO inhibitor 1-methyl-D-tryptophan resulted in a twofold increase in CD8 ${ }^{+}$ T lymphocytes in the brain and an $89 \%$ reduction in the HIV-1-infected monocyte-derived macrophages. It is important to note, though, that in the followup study of Franchini et al. CTLA-4 blockade led to increased immune activation and viral replication, particularly at the mucosal sites but did not increase virus-specific responses [29]. Moreover, in clinical 
trials involving the use of an anti-CTLA- $4 \mathrm{mAb}$ for melanoma patients, up to $40 \%$ of patients had grade 3 or 4 immune-related adverse events [75].

Adenosine production is an important mechanism of Treg-induced suppression. The Treg expression of CD39 allows for the increased extracellular production of adenosine. Once adenosine binds to the adenosine A2A receptor in effector $\mathrm{T}$ cells, cytoplasmic cAMP levels increase, which in turn, inhibits NFKB activation and consequently T-cell proliferation $[76,77]$. Blockade of this pathway is a strategy that can counteract Treg suppression. Indeed, Tregs from CD39-null mice fail to suppress T-cell proliferation [77]. Drugs that can inhibit the A2A receptor pathway could then be used to boost anti-HIV responses.

The advantage of blocking only a specific mechanism of suppression of Tregs is that it may not completely inhibit Treg function and might prevent the enhancement of autoimmunity. In addition, it may be ideal if there is also a specific suppressive mechanism responsible for preventing the persistent immune activation in HIV. It is important, then, to identify the specific mechanism by which Tregs are involved in HIV infection in order to test strategies for enhancing immune control. We have shown that expression of both GITR and CTLA-4 are markedly increased in Tregs from HIV-1-infected patients compared with seronegative controls [63]. Additional trials testing the efficacy of selective inhibition of these receptors in combination with other immunotherapeutic strategies may be beneficial.

\section{Conclusion}

The conflicting results of various Treg studies in HIV highlight the complex interactions that are involved in the immunopathogenesis of HIV infection. A major problem in Treg depletion or inactivation strategies is that there is still no specific marker for these cells. Unlike the use of FOXP3 in mice, commonly used markers such as CD25 and FOXP3 are also seen in other T-cell subsets and depleting them based on these may also affect other effector T-cell functions. Another important hurdle in this form of immunotherapy is that the exact role of Tregs in HIV is still a matter of debate. This becomes important because Tregs have been reported to be beneficial in suppressing the persistent immune activation that is characteristic of chronic HIV infection [78]. In other disease states, such as cancer, where immune activation does not play as important a role, depletion of Tregs may only lead to increased immune response against the cancer cells with only autoimmunity as the possible harmful side effect. In HIV, Treg inactivation may lead to increased immune activation which, in turn, may further increase the target cells for the virus and decrease the half life of $\mathrm{T}$ cells. Moreover, decrease in Tregs has not only been associated with increased cellular activation but also with immune exhaustion as shown by increased expression of PD-1 [61]. As such, simply applying Treg immunotherapeutic strategies tested in diseases other than HIV may pose a number of problems, one of which is the risk of further progression of HIV infection. We must therefore be cautious in designing such studies.

\section{Future perspective}

Owing to the significant role Tregs play in various medical conditions, research regarding new mechanisms of suppression and specific markers will continue in an effort to find ways of treating diseases through specific modulation of the Treg subset. New discoveries will lead to more promising strategies of immunotherapy. We must recognize, though, that immunotherapy for HIV infection is in its infancy, well behind the advances made in immunotherapy of various cancers. We are likely to encounter setbacks and obstacles in the various immunotherapeutic approaches currently in use, in part due to the counter effects of Tregs and other immunoregulatory mechanisms. As the exact role of these cells in HIV has not been fully defined, the different possible strategies that we have enumerated may not 
necessarily lead to their expected effects. Understanding Tregs in HIV will be made more difficult by the fact that a number of different cells with regulatory functions have been discovered since the emergence of Tregs in the 1990s. These include myeloid-derived suppressor cells, double-negative Tregs, and regulatory B cells [79-81]. The role of these cells in HIV infection is starting to be investigated, and the results of the studies will likely make the already complex immunologic networks involved in the pathogenesis of HIV more complicated.

The significance of Tregs and other immunoregulatory cells in HIV goes beyond strategies for immunotherapy. As the focus of HIV research is slowly shifting towards the management of coinfections with malaria, TB and HCV, and the identification of latent HIV reservoirs in the hope of discovering the much elusive cure for HIV, the role of Tregs will continue to be of importance. Since Treg suppression has also been described in malaria, TB, and HCV [82-85], do the bystander immunosuppression effects brought about by HIV and these other infections exert a significant effect on one other, thereby complicating therapies in coinfected patients? Also, as we have yet to define what Tregs do in chronically suppressed HIV patients, an important question is whether the effect of agents administered to make latent HIV reservoirs express virus will be countered by Tregs in order to prevent increased immune activation. These questions are likely to be addressed in the coming years.

In the end, what is necessary is to further elucidate the different immunoregulatory mechanisms at play in HIV infection. Investigating the interactions of Tregs with other regulatory cells in the background of HIV infection are important in order to determine the cellular or molecular pathways that could be altered to boost the body's immune control of HIV without worsening cellular immune activation.

\section{Acknowledgments}

Charles Rinaldo is Chairman and Professor of the Department of Infectious Diseases and Microbiology at the University of the Pittsburgh Graduate School of Public Health and has received research funding from the US NIH (U19-AI055794 and R37-AI41870).

\section{Bibliography}

Papers of special note have been highlighted as:

- of interest

- of considerable interest

1. Sakaguchi S, Sakaguchi N, Asano M, Itoh M, Toda M. Immunologic self-tolerance maintained by activated T cells expressing IL-2 receptor $\alpha$-chains (CD25). Breakdown of a single mechanism of self-tolerance causes various autoimmune diseases. J Immunol. 1995; 155(3):1151-1164. [PubMed: 7636184] - Seminal study that first described a subset of T cells that function to maintain selftolerance by downregulating the immune response to self antigens.

2. Kuniyasu Y, Takahashi T, Itoh M, Shimizu J, Toda G, Sakaguchi S. Naturally anergic and suppressive $\mathrm{CD} 25^{+} \mathrm{CD} 4^{+} \mathrm{T}$ cells as a functionally and phenotypically distinct immunoregulatory $\mathrm{T}$ cell subpopulation. Int Immunol. 2000; 12(8):1145-1155. [PubMed: 10917889]

3. Taams, L.; Akbar, AN.; Wauben, MHM., editors. Regulatory T Cells In Inflammation. Birkhäuser; Basel, Switzerland: 2005.

4. von Herrath MG, Harrison LC. Antigen-induced regulatory T cells in autoimmunity. Nat Rev Immunol. 2003; 3(3):223-232. [PubMed: 12658270]

5. Belkaid Y, Tarbell K. Regulatory T cells in the control of host-microorganism interactions (*). Annu Rev Immunol. 2009; 27:551-589. [PubMed: 19302048] -- Extensive review on the role of regulatory $\mathrm{T}$ cells (Treg) in different infections and includes a discussion of different strategies of Treg manipulation as immunotherapy. 
6. Sakaguchi S, Miyara M, Costantino CM, Hafler DA. FOXP3 ${ }^{+}$regulatory T cells in the human immune system. Nat Rev Immunol. 2010; 10(7):490-500. [PubMed: 20559327]

7. Itoh M, Takahashi T, Sakaguchi N, et al. Thymus and autoimmunity: production of $\mathrm{CD} 25^{+} \mathrm{CD} 4^{+}$ naturally anergic and suppressive $\mathrm{T}$ cells as a key function of the thymus in maintaining immunologic self-tolerance. J Immunol. 1999; 162(9):5317-5326. [PubMed: 10228007]

8. Hori S, Nomura T, Sakaguchi S. Control of regulatory T cell development by the transcription factor Foxp3. Science. 2003; 299(5609):1057-1061. [PubMed: 12522256]

9. Takahashi T, Tagami T, Yamazaki S, et al. Immunologic self-tolerance maintained by $\mathrm{CD} 25^{+} \mathrm{CD} 4^{+}$ regulatory $\mathrm{T}$ cells constitutively expressing cytotoxic T lymphocyte-associated antigen 4 . J Exp Med. 2000; 192(2):303-310. [PubMed: 10899917]

10. McHugh RS, Whitters MJ, Piccirillo CA, et al. CD4 ${ }^{+} \mathrm{CD} 25^{+}$immunoregulatory T cells: gene expression analysis reveals a functional role for the glucocorticoid-induced TNF receptor. Immunity. 2002; 16(2):311-323. [PubMed: 11869690]

11. Mandapathil M, Szczepanski MJ, Szajnik M, et al. Adenosine and prostaglandin E2 cooperate in the suppression of immune responses mediated by adaptive regulatory T cells. J Biol Chem. 2010; 285(36):27571-27580. [PubMed: 20558731]

12. Mandapathil M, Lang S, Gorelik E, Whiteside TL. Isolation of functional human regulatory T cells (Treg) from the peripheral blood based on the CD39 expression. J Immunol Methods. 2009; 346(1-2):55-63. [PubMed: 19450601] - Described another method of isolating functionally suppressive Treg without using the intracellular staining with forkhead box (FOX)P3.

13. Borsellino G, Kleinewietfeld M, Di Mitri D, et al. Expression of ectonucleotidase CD39 by Foxp3 ${ }^{+}$ Treg cells: hydrolysis of extracellular ATP and immune suppression. Blood. 2007; 110(4):12251232. [PubMed: 17449799]

14. Barthlott T, Moncrieffe $\mathrm{H}$, Veldhoen $\mathrm{M}$, et al. $\mathrm{CD} 25^{+} \mathrm{CD} 4^{+} \mathrm{T}$ cells compete with naive $\mathrm{CD} 4^{+} \mathrm{T}$ cells for IL-2 and exploit it for the induction of IL-10 production. Int Immunol. 2005; 17(3):279288. [PubMed: 15684039]

15. Munn DH, Sharma MD, Mellor AL. Ligation of B7-1/B7-2 by human CD4 ${ }^{+}$T cells triggers indoleamine 2,3-dioxygenase activity in dendritic cells. J Immunol. 2004; 172(7):4100-4110. [PubMed: 15034022]

16. Sojka DK, Huang YH, Fowell DJ. Mechanisms of regulatory T-cell suppression - a diverse arsenal for a moving target. Immunology. 2008; 124(1):13-22. [PubMed: 18346152]

17. Cao X, Cai SF, Fehniger TA, et al. Granzyme B and perforin are important for regulatory T cellmediated suppression of tumor clearance. Immunity. 2007; 27(4):635-646. [PubMed: 17919943]

18. Fazekas de St Groth B, Landay AL. Regulatory T cells in HIV infection: pathogenic or protective participants in the immune response? AIDS. 2008; 22(6):671-683. [PubMed: 18356596] - Lists both murine and human studies in Treg identification and summarizes important Treg studies in HIV infection.

19. Seddiki N, Kelleher AD. Regulatory T cells in HIV infection: who's suppressing what? Curr HIV/ AIDS Rep. 2008; 5(1):20-26. [PubMed: 18417031]

20. Kinter A, McNally J, Riggin L, Jackson R, Roby G, Fauci AS. Suppression of HIV-specific T cell activity by lymph node $\mathrm{CD} 25^{+}$regulatory T cells from HIV-infected individuals. Proc Natl Acad Sci USA. 2007; 104(9):3390-3395. [PubMed: 17360656] - Described the increased frequency of CD25 ${ }^{\text {hi }}$ FOXP ${ }^{+}$Treg in lymph nodes compared with Treg in peripheral blood and demonstrated that the lymph nodes Treg exhibited potent HIV-specific suppressive function.

21. Krathwohl MD, Schacker TW, Anderson JL. Abnormal presence of semimature dendritic cells that induce regulatory T cells in HIV-infected subjects. J Infect Dis. 2006; 193(4):494-504. [PubMed: $16425128]$

22. Ji J, Cloyd MW. HIV-1 binding to $\mathrm{CD} 4$ on $\mathrm{CD} 4{ }^{+} \mathrm{CD} 25^{+}$regulatory T cells enhances their suppressive function and induces them to home to, and accumulate in, peripheral and mucosal lymphoid tissues: an additional mechanism of immunosuppression. Int Immunol. 2009; 21(3):283294. [PubMed: 19208751] -- Demonstrates how HIV binding to Treg causes a two- to five-fold increase in Treg suppressive activity, an increase in Treg survival, and an accumulation of Treg in peripheral and mucosal lymphoid tissue. 
23. Becker C, Taube C, Bopp T, et al. Protection from graft-versus-host disease by HIV-1 envelope protein gp120-mediated activation of human $\mathrm{CD} 4{ }^{+} \mathrm{CD} 25^{+}$regulatory T cells. Blood. 2009; 114(6): 1263-1269. [PubMed: 19439734]

24. Kinter AL, Horak R, Sion M, et al. CD25+ regulatory T cells isolated from HIV-infected individuals suppress the cytolytic and nonlytic antiviral activity of HIV-specific $\mathrm{CD}^{+} \mathrm{T}$ cells in vitro. AIDS Res Hum Retroviruses. 2007; 23(3):438-450. [PubMed: 17411377]

25. Thorborn G, Pomeroy L, Isohanni H, Perry M, Peters B, Vyakarnam A. Increased sensitivity of $\mathrm{CD} 4{ }^{+} \mathrm{T}$-effector cells to $\mathrm{CD} 4{ }^{+} \mathrm{CD} 25^{+}$Treg suppression compensates for reduced Treg number in asymptomatic HIV-1 infection. PLoS ONE. 2010; 5(2):E9254. [PubMed: 20174666]

26. Ndhlovu LC, Loo CP, Spotts G, Nixon DF, Hecht FM. FOXP3 expressing CD1271o CD4 ${ }^{+}$T cells inversely correlate with $\mathrm{CD} 38^{+} \mathrm{CD} 8^{+} \mathrm{T}$ cell activation levels in primary HIV-1 infection. $\mathrm{J}$ Leukoc Biol. 2008; 83(2):254-262. [PubMed: 17982112]

27. Jiao Y, Fu J, Xing S, et al. The decrease of regulatory T cells correlates with excessive activation and apoptosis of $\mathrm{CD}^{+} \mathrm{T}$ cells in HIV-1-infected typical progressors, but not in long-term nonprogressors. Immunology. 2009; 128(1 Suppl):E366-E375. [PubMed: 19016904]

28. Giorgi JV, Hultin LE, McKeating JA, et al. Shorter survival in advanced human immunodeficiency virus type 1 infection is more closely associated with T lymphocyte activation than with plasma virus burden or virus chemokine coreceptor usage. J Infect Dis. 1999; 179(4):859-870. [PubMed: 10068581] - One of the first studies correlating immune activation with HIV disease progression.

29. Cecchinato V, Tryniszewska E, Ma ZM, et al. Immune activation driven by CTLA-4 blockade augments viral replication at mucosal sites in simian immunodeficiency virus infection. $\mathrm{J}$ Immunol. 2008; 180(8):5439-5447. [PubMed: 18390726]

30. Weiss L, Piketty C, Assoumou L, et al. Relationship between regulatory T cells and immune activation in human immunodeficiency virus-infected patients interrupting antiretroviral therapy. PLoS ONE. 2010; 5(7):E11659. [PubMed: 20657770] - Demonstrated the dual role of Treg in HIV infection: decreasing immune activation and suppressing immune response to the virus.

31. Brenchley JM, Paiardini M, Knox KS, et al. Differential Th17 CD4 T-cell depletion in pathogenic and nonpathogenic lentiviral infections. Blood. 2008; 112(7):2826-2835. [PubMed: 18664624]

32. Favre D, Lederer S, Kanwar B, et al. Critical loss of the balance between Th17 and T regulatory cell populations in pathogenic SIV infection. PLoS Pathog. 2009; 5(2):E1000295. [PubMed: 19214220] - Highly important study demonstrating the negative correlation of T-helper (Th)17:Treg ratio with sustained systemic immune activation in the blood and lymph nodes of pigtailed macaques infected with simian immunodeficiency virus (SIV). The study highlights the possible roles Treg and Th17 cells play in lentiviral infections.

33. Prendergast A, Prado JG, Kang YH, et al. HIV-1 infection is characterized by profound depletion of CD161 ${ }^{+}$Th17 cells and gradual decline in regulatory T cells. AIDS. 2010; 24(4):491-502. [PubMed: 20071976]

34. Favre D, Mold J, Hunt PW, et al. Tryptophan catabolism by indoleamine 2,3-dioxygenase 1 alters the balance of Th17 to regulatory T cells in HIV disease. Sci Transl Med. 2010; 2(32):32ra36. -• Important follow-up study investigating the role of indoleamine 2,3 deoxygenase in altering the Th17/Treg balance and in the chronic inflammatory state observed in progressive HIV disease.

35. Cao W, Jamieson BD, Hultin LE, Hultin PM, Detels R, et al. Regulatory T cell expansion and immune activation during untreated HIV type 1 infection are associated with disease progression. AIDS Res Hum Retroviruses. 2009; 25(2):183-191. [PubMed: 19239357] - Case-control study results showed positive correlation of Treg expansion leading to immune activation and disease progression.

36. Kovacs JA, Baseler M, Dewar RJ, et al. Increases in CD4 T lymphocytes with intermittent courses of interleukin-2 in patients with human immunodeficiency virus infection. A preliminary study. N Engl J Med. 1995; (9):567-575. [PubMed: 7646637]

37. Kovacs JA, Vogel S, Albert JM, et al. Controlled trial of interleukin-2 infusions in patients infected with the human immunodeficiency virus. N Engl J Med. 1996; 335(18):1350-1356. [PubMed: 8857018]

38. Vogler MA, Teppler H, Gelman R, et al. Daily low-dose subcutaneous interleukin-2 added to single- or dual-nucleoside therapy in HIV infection does not protect against $\mathrm{CD} 4^{+} \mathrm{T}$-cell decline 
or improve other indices of immune function: results of a randomized controlled clinical trial (ACTG 248). J Acquir Immune Defic Syndr. 2004; 36(1):576-587. [PubMed: 15097300]

39. Goujard C, Marcellin F, Hendel-Chavez H, et al. Interruption of antiretroviral therapy initiated during primary HIV-1 infection: impact of a therapeutic vaccination strategy combined with interleukin (IL)-2 compared with IL-2 alone in the ANRS 095 randomized study. AIDS Res Hum Retroviruses. 2007; 23(9):1105-1113. [PubMed: 17919105]

40. Abrams D, Levy Y, Losso MH, et al. Interleukin-2 therapy in patients with HIV infection. N Engl J Med. 2009; 361(16):1548-1559. [PubMed: 19828532]

41. Asmuth DM, Murphy RL, Rosenkranz SL, et al. Safety, tolerability, and mechanisms of antiretroviral activity of pegylated interferon $\alpha$-2a in HIV-1-monoinfected participants: a Phase II clinical trial. J Infect Dis. 2010; 201(11):1686-1696. [PubMed: 20420510]

42. Levy Y, Lacabaratz C, Weiss L, et al. Enhanced T cell recovery in HIV-1-infected adults through IL-7 treatment. J Clin Invest. 2009; 119(4):997-1007. [PubMed: 19287090]

43. Sereti I, Dunham RM, Spritzler J, et al. IL-7 administration drives T cell-cycle entry and expansion in HIV-1 infection. Blood. 2009; 113(25):6304-6314. [PubMed: 19380868]

44. Day CL, Kaufmann DE, Kiepiela P, et al. PD-1 expression on HIV-specific T cells is associated with T-cell exhaustion and disease progression. Nature. 2006; 443(7109):350-354. [PubMed: 16921384]

45. Blackburn SD, Shin H, Haining WN, et al. Coregulation of $\mathrm{CD}^{+} \mathrm{T}$ cell exhaustion by multiple inhibitory receptors during chronic viral infection. Nat Immunol. 2009; 10(1):29-37. [PubMed: 19043418]

46. Macatangay BJ, Rinaldo CR. PD-1 blockade: a promising immunotherapy for HIV? Cellscience. 2009; 5(4):61-65. [PubMed: 20490361]

47. Kassu A, Marcus RA, D'Souza MB, et al. Regulation of virus-specific CD4 ${ }^{+} \mathrm{T}$ cell function by multiple costimulatory receptors during chronic HIV infection. J Immunol. 2010; 185(5):30073018. [PubMed: 20656923] - Investigated the relationship of different costimulatory receptors with HIV replication and found that expression of programmed death receptor (PD)-1, cytotoxic T lymphocyte-associated antigen (CTLA)-4 and T-cell immunoglobulin and mucin domaincontaining molecule (TIM)-3 together strongly correlated with plasma viremia.

48. Velu V, Titanji K, Zhu B, et al. Enhancing SIV-specific immunity in vivo by PD-1 blockade. Nature. 2009; 458(7235):206-210. [PubMed: 19078956] - First in vivo study showing the enhancement of SIV-specific immune response after administering a PD-1 antibody to SIVinfected macaques.

49. Breton G, Yassine-Diab B, Cohn L, et al. siRNA knockdown of PD-L1 and PD-L2 in monocytederived dendritic cells only modestly improves proliferative responses to $\mathrm{Gag}$ by $\mathrm{CD}^{+} \mathrm{T}$ cells from HIV-1-infected individuals. J Clin Immunol. 2009; 29(5):637-645. [PubMed: 19562472]

50. Connolly NC, Whiteside TL, Wilson C, Kondragunta V, Rinaldo CR, Riddler SA. Therapeutic immunization with human immunodeficiency virus type 1 (HIV-1) peptide-loaded dendritic cells is safe and induces immunogenicity in HIV-1-infected individuals. Clin Vaccine Immunol. 2008; 15(2):284-292. [PubMed: 17942609]

51. Routy JP, Boulassel MR, Yassine-Diab B, et al. Immunologic activity and safety of autologous HIV RNA-electroporated dendritic cells in HIV-1 infected patients receiving antiretroviral therapy. Clin Immunol. 2010; 134(2):140-147. [PubMed: 19889582]

52. Lu W, Arraes LC, Ferreira WT, Andrieu JM. Therapeutic dendritic-cell vaccine for chronic HIV-1 infection. Nat Med. 2004; 10(12):1359-1365. [PubMed: 15568033]

53. Garcia F, Lejeune M, Climent N, et al. Therapeutic immunization with dendritic cells loaded with heat-inactivated autologous HIV-1 in patients with chronic HIV-1 infection. J Infect Dis. 2005; 191(10):1680-1685. [PubMed: 15838795]

54. Wei S, Kryczek I, Edwards RP, et al. Interleukin-2 administration alters the CD4 ${ }^{+} \mathrm{FOXP} 3^{+} \mathrm{T}$-cell pool and tumor trafficking in patients with ovarian carcinoma. Cancer Res. 2007; 67(15):74877494. [PubMed: 17671219] - Cancer study showing proliferation of existent Treg after administration of IL-2 therapy together with increased C-X-C chemokine receptor-4 expression allowing them to migrate to the tumor. 
55. Weiss L, Letimier FA, Carriere M, et al. In vivo expansion of naive and activated $\mathrm{CD} 4^{+} \mathrm{CD} 25^{+} \mathrm{FOXP}^{+}$regulatory $\mathrm{T}$ cell populations in interleukin-2-treated HIV patients. Proc Natl Acad Sci USA. 2010; 107(23):10632-10637. [PubMed: 20498045] - Demonstrated expansion of the Treg subset after IL-2 therapy, which the authors hypothesize is a possible explanation for the higher relative risk of progression to AIDS in subjects who had greater CD4 count expansion while on IL-2 therapy.

56. Ndhlovu LC, Sinclair E, Epling L, et al. IL-2 immunotherapy to recently HIV-1 infected adults maintains the numbers of IL-17 expressing $\mathrm{CD}^{+} \mathrm{T}(\mathrm{T}(\mathrm{H}) 17)$ cells in the periphery. $\mathrm{J}$ Clin Immunol. 2010; 30(5):681-692. [PubMed: 20571894]

57. Levings MK, Sangregorio R, Galbiati F, Squadrone S, de Waal Malefyt R, Roncarolo MG. IFN- $\alpha$ and IL-10 induce the differentiation of human type $1 \mathrm{~T}$ regulatory cells. J Immunol. 2001; 166(9): 5530-5539. [PubMed: 11313392]

58. Luik A, Knapp S, Thursz M, Thomas HC, Schlaak JF. Autoregulatory role of interleukin-10 in hepatitis C patients treated with IFN- $\alpha$. J Interferon Cytokine Res. 2004; 24(10):585-593. [PubMed: 15626155]

59. Franceschini D, Paroli M, Francavilla V, et al. PD-L1 negatively regulates CD $4^{+} \mathrm{CD} 25^{+} \mathrm{Foxp} 3^{+}$ Tregs by limiting STAT-5 phosphorylation in patients chronically infected with HCV. J Clin Invest. 2009; 119(3):551-564. [PubMed: 19229109]

60. Radziewicz H, Dunham RM, Grakoui A. PD-1 tempers Tregs in chronic HCV infection. J Clin Invest. 2009; 119(3):450-453. [PubMed: 19306502]

61. Sachdeva M, Fischl MA, Pahwa R, Sachdeva N, Pahwa S. Immune exhaustion occurs concomitantly with immune activation and decrease in regulatory $\mathrm{T}$ cells in viremic chronically HIV-1-infected patients. J Acquir Immune Defic Syndr. 2010; 54(5):447-454. [PubMed: 20463584] - Showed that in viremic HIV patients, Treg frequency negatively correlated with both immune activation (HLA-DR and CD38 coexpression) and immune exhaustion (expression of PD-1).

62. Amarnath S, Costanzo CM, Mariotti J, et al. Regulatory T cells and human myeloid dendritic cells promote tolerance via programmed death ligand-1. PLoS Biol. 2010; 8(2):E1000302. [PubMed: 20126379] - Demonstrated an important mechanism of suppression by Treg, which is to upregulate the expression of PD-L1 in myeloid dendritic cells.

63. Macatangay BJ, Szajnik ME, Whiteside TL, Riddler SA, Rinaldo CR. Regulatory T cell suppression of Gag-specific CD8 T cell polyfunctional response after therapeutic vaccination of HIV-1-infected patients on ART. PLoS ONE. 2010; 5(3):e9852. [PubMed: 20352042] • Demonstrated increase in HIV-specific Treg suppressive function in HIV subjects after receiving an autologous dendritic cell HIV vaccine. The removal of Treg led to an increase on CD8 T-cell polyfunctional response to Gag peptide.

64. Banerjee DK, Dhodapkar MV, Matayeva E, Steinman RM, Dhodapkar KM. Expansion of FOXP3 high regulatory $\mathrm{T}$ cells by human dendritic cells (DCs) in vitro and after injection of cytokinematured DCs in myeloma patients. Blood. 2006; 108(8):2655-2661. [PubMed: 16763205] • Cancer study that demonstrated that dendritic cells can induce the expansion of Treg and is dependent on cell-cell contact.

65. Berntsen A, Brimnes MK, thor Straten P, Svane IM. Increase of circulating $\mathrm{CD} 4{ }^{+} \mathrm{CD} 25$ highFoxp $3^{+}$regulatory $\mathrm{T}$ cells in patients with metastatic renal cell carcinoma during treatment with dendritic cell vaccination and low-dose interleukin-2. J Immunother. 2010; 33(4): 425-434. [PubMed: 20386464]

66. Onishi Y, Fehervari Z, Yamaguchi T, Sakaguchi S. Foxp3 ${ }^{+}$natural regulatory T cells preferentially form aggregates on dendritic cells in vitro and actively inhibit their maturation. Proc Natl Acad Sci USA. 2008; 105(29):10113-10118. [PubMed: 18635688] • Another important study demonstrating Treg and dendritic cell interactions. Treg were shown to aggregate around the dendritic cells and exert a CD80/86 down modulating effect, even in the presence of strong dendritic cell-maturing stimuli.

67. O'Gorman WE, Dooms H, Thorne SH, et al. The initial phase of an immune response functions to activate regulatory T cells. J Immunol. 2009; 183(1):332-339. [PubMed: 19542444] •- Important study demonstrating the activation of Treg as the initial event in the T-cell immune response. 
68. Valentin A, von Gegerfelt A, Rosati M, et al. Repeated DNA therapeutic vaccination of chronically SIV-infected macaques provides additional virological benefit. Vaccine. 2010; 8(8):1962-1974. [PubMed: 20188252]

69. Rech AJ, Vonderheide RH. Clinical use of anti-CD25 antibody daclizumab to enhance immune responses to tumor antigen vaccination by targeting regulatory T cells. Ann NY Acad Sci. 2009; 1174:99-106. [PubMed: 19769742]

70. Jacobs JF, Punt CJ, Lesterhuis WJ, et al. Dendritic cell vaccination in combination with anti-CD25 monoclonal antibody treatment: a Phase I/II study in metastatic melanoma patients. Clin Cancer Res. 2010; 16(20):5067-5078. [PubMed: 20736326]

71. Saha A, Chatterjee SK. Combination of CTL-associated antigen-4 blockade and depletion of CD25 regulatory $\mathrm{T}$ cells enhance tumour immunity of dendritic cell-based vaccine in a mouse model of colon cancer. Scand J Immunol. 2010; 71(2):70-82. [PubMed: 20384858]

72. Coe D, Begom S, Addey C, White M, Dyson J, Chai JG. Depletion of regulatory T cells by antiGITR $\mathrm{mAb}$ as a novel mechanism for cancer immunotherapy. Cancer Immunol Immunother. 2010; 59(9):1367-1377. [PubMed: 20480365]

73. Morrow MP, Pankhong P, Laddy DJ, et al. Comparative ability of IL-12 and IL-28B to regulate Treg populations and enhance adaptive cellular immunity. Blood. 2009; 113(23):5868-5877. [PubMed: 19304955]

74. Hryniewicz A, Boasso A, Edghill-Smith Y, et al. CTLA-4 blockade decreases TGF- $\beta$, IDO, and viral RNA expression in tissues of SIVmac251-infected macaques. Blood. 2006; 108(12):38343842. [PubMed: 16896154]

75. Sarnaik AA, Weber JS. Recent advances using anti-CTLA-4 for the treatment of melanoma. Cancer J. 2009; 15(3):169-173. [PubMed: 19556898]

76. Hershfield MS. New insights into adenosine-receptor-mediated immunosuppression and the role of adenosine in causing the immunodeficiency associated with adenosine deaminase deficiency. Eur $\mathbf{J}$ Immunol. 2005; 35(1):25-30. [PubMed: 15580654]

77. Deaglio S, Dwyer KM, Gao W, et al. Adenosine generation catalyzed by CD39 and CD73 expressed on regulatory T cells mediates immune suppression. J Exp Med. 2007; 204(6):12571265. [PubMed: 17502665]

78. Douek DC, Roederer M, Koup RA. Emerging concepts in the immunopathogenesis of AIDS. Annu Rev Med. 2009; 60:471-484. [PubMed: 18947296] -- Excellent review of recent developments in HIV immunopathogenesis, which includes chronic immune activation and T-cell dysfunction.

79. Thomson CW, Lee BP, Zhang L. Double-negative regulatory T cells: non-conventional regulators. Immunol Res. 2006; 35(1-2):163-178. [PubMed: 17003518]

80. Bouaziz JD, Yanaba K, Tedder TF. Regulatory B cells as inhibitors of immune responses and inflammation. Immunol Rev. 2008; 224:201-214. [PubMed: 18759928]

81. Gabrilovich DI, Nagaraj S. Myeloid-derived suppressor cells as regulators of the immune system. Nat Rev Immunol. 2009; 9(3):162-174. [PubMed: 19197294]

82. Scholzen A, Minigo G, Plebanski M. Heroes or villains? T regulatory cells in malaria infection. Trends Parasitol. 2010; 26(1):16-25. [PubMed: 19914134]

83. He XY, Xiao L, Chen HB, et al. T regulatory cells and Th1/Th2 cytokines in peripheral blood from tuberculosis patients. Eur J Clin Microbiol Infect Dis. 2010; 29(6):643-650. [PubMed: 20306324]

84. Sturm N, Thelu MA, Camous X, et al. Characterization and role of intra-hepatic regulatory T cells in chronic hepatitis C pathogenesis. J Hepatol. 2010; 53(1):25-35. [PubMed: 20452085]

85. Rallon NI, Barreiro P, Soriano V, Garcia-Samaniego J, Lopez M, Benito JM. Elevated TGF- $\beta 1$ levels might protect HCV/HIV-coinfected patients from liver fibrosis. Eur J Clin Invest. 2010 Epub ahead of print. 10.1111/j.1365-2362.2010.02381 